\title{
EEG changes associated with autistic spectrum disorders
}

\author{
Nash N Boutros ${ }^{1 *}$, Renee Lajiness-O'Neill ${ }^{2}$, Andrew Zillgitt ${ }^{3}$, Anette E Richard ${ }^{2}$ and Susan M Bowyer ${ }^{3,4,5}$
}

\footnotetext{
* Correspondence: boutrosn@umkc.edu 'Department of Psychiatry and Neurosciences, University of Missouri Kansas City, Center for Behavioral Medicine, 1000 E. 24th Street, Kansas City, MO 64108, USA Full list of author information is available at the end of the article
}

\begin{abstract}
Autism Spectrum Disorders (ASD) are an etiologically and clinically heterogeneous group of neurodevelopmental disorders. The pathophysiology of ASD remains largely unknown. One essential and well-documented observation is high comorbidity between ASD and epilepsy. Electroencephalography (EEG) is the most widely used tool to detect epileptic brain activity. The EEG signal is characterized by a high temporal resolution (on the order of milliseconds) allowing for precise temporal examination of cortical activity. This review addresses the main EEG findings derived from both the standard or qualitative (visually inspected) EEG and the quantitative (computer analyzed) EEG during resting state in individuals with ASD. The bulk of the evidence supports significant connectivity disturbances in ASD that are possibly widespread with two specific aspects: over-connectivity in the local networks and under-connectivity in the long-distance networks. Furthermore, the review suggested that disruptions appear more severe in later developing parts of the brain (e.g., prefrontal cortex). Based on available information, from both the qualitative and quantitative EEG literature, we postulate a preliminary hypothesis that increased cortical excitability may contribute to the significant overlap between ASD and epilepsy and may be contributing to the connectivity deviations noted. As the presence of a focal epileptic discharge is a clear indication of such hyperexcitability, we conclude that the presence of epileptic discharges is a potential biomarker at least for a subgroup of ASD.

Keywords: Autism spectrum disorders (ASD), Epilepsy, Electroencephalography, Standard EEG, Quantified EEG, Epileptic discharges, Isolated epileptic discharges (IEDs), Coherence, Coherence source imaging (CSI)
\end{abstract}

\section{Biomed Central}

\section{Introduction}

\section{Clinical manifestations and heterogeneity}

Autistic spectrum disorder (ASD) patients encompass a heterogeneous group of individuals with early childhood onset of deficits in social interaction and language development, a restricted repertoire of interests and activities, as well as a wide range of cognitive skills ranging from severe deficits to high functioning individuals. Behavior often worsens and cognitive decline may also be observed. At least some children with ASD are apparently healthy prior to the onset of the disorder. In some of these children, onset of deterioration may be as late as mid-childhood. Despite much research into the biological factors contributing to the development of ASD, the constellation of factors necessary for the syndrome to manifest remains unclear.

(c) 2015 Boutros et al.; licensee BioMed Central. This is an Open Access article distributed under the terms of the Creative Commons Attribution License (http://creativecommons.org/licenses/by/4.0), which permits unrestricted use, distribution, and reproduction in any medium, provided the original work is properly credited. The Creative Commons Public Domain Dedication waiver (http:// creativecommons.org/publicdomain/zero/1.0/) applies to the data made available in this article, unless otherwise stated. 


\section{Evidence for neurological involvement in ASD}

Evidence of neurological contributions to the ASD syndrome has been accumulating. The initial report by Kanner (1943), in which he described 11 children with autism, provided important hints for a significant neurological component to this syndrome. One child had seizures, three were mute, and five were macrocephalic. Despite these observations, only when the first report of EEG abnormalities in this population was published was a more serious consideration of an organic/neurological etiology entertained (Gubbay et al. 1970). In an early report of 25 children with ASD, 30\% had seizures and a full $80 \%$ had abnormal EEGs (the majority of children with seizures had abnormal EEGs) (Gubbay et al. 1970). Furthermore, epilepsy seems to be a major factor contributing to the severity of behavioral problems in ASD and is strongly correlated with worse cognitive functioning (Ošlejšková et al. 2007), with only $8 \%$ of individuals with ASD diagnosed with intellectual disability in the absence of epilepsy (Amiet et al. 2008; 2013). In fact, the majority of available studies suggest that approximately one third of children with ASD develop epilepsy (Gillberg 1991). The occurrence of epilepsy in ASD has been intensively investigated (Tuchman \& Rapin 1997; Hrdlicka et al. 2004; Canitano et al. 2005; Hughes \& Melyn 2005). DeLong \& Nohria (1994) obtained both complete neurological assessment (including karyotyping) and psychiatric family history from 40 children with ASD. Twenty patients had positive neurological or genetic findings, 18 of which had negative psychiatric family histories. Fourteen of the 20 patients who were without neurological findings had family histories of affective disorders; these patients tended to be higher functioning. These findings underscore the significant heterogeneity within this patient population.

\section{Role of epileptic activity}

Despite estimates of high comorbidity of epileptic activity with ASD, it is not known if the presence of epileptiform discharges, in the absence of seizures, contributes to the symptom presentation of ASD. Thus, a major purpose of this report is to define the prevalence of epileptic activity in non-epileptic (or pre-epileptic) ASD individuals and speculate on the possible role of such activity in abnormal neural connectivity in these individuals. The term isolated epileptiform discharges (IEDs) is used here to denote the occurrence of epileptiform discharges in the complete absence of identifiable seizures as opposed to interictal spike discharges (ISD) occurring between seizures. The clinical significance and therapeutic implications of the detection of IEDs in a child on the autism spectrum or neurodevelopmental disorders with similar behavioral phenotypes are unclear. A notable exception is for the Landau-Kleffner syndrome (LKS) in which the IEDs are considered etiologic for the development of the associated aphasia (Stefanatos et al. 2002). While the clinical significance of the presence of IEDs in non-epileptic individuals remains unknown there is presumptive evidence that IEDs are not simply incidental findings and that they may have deleterious effects that are in need of further investigation (Boutros 2009). For example, Findji et al. (1979) described an 8-year-old child whose behavior alternated between excitation and autism with stereotypies. The EEG showed a temporo-parietal sharp wave pattern of 5 discharges/second lasting from 1 second to 20 minutes. However, these discharges (even the prolonged ones) were not associated with any clinical signs of epilepsy. While there were no clear correlation between the discharges and particular aberrant behaviors, epileptic discharges were 
significantly more frequent during periods when the child was left alone and decreased when the child interacted with others. We have recently proposed that IEDs may be reflective of some degree of cortical hyperexcitability (Boutros et al. 2014); however, a strong link between IEDs in the absence of seizures and behavioral symptoms remains far from being well established (So 2010).

\section{Introduction to EEG studies in ASD}

EEG is a widely used technique to investigate brain functions in healthy individuals and in those with medical and psychiatric problems. EEG can be used to examine brain activity either during rest, or during evoked brain responses using specific tasks known to elicit these evoked responses as well as by examining the effects of specific tasks (e.g., face recognition) on the ongoing EEG signal. These two techniques (i.e., taskrelated EEG changes and evoked potentials) of examining the EEG signal in ASD also have voluminous bodies of literature associated with them. In the current review we focus on the resting or un-activated/unevoked state as it is essential to be cognizant of any abnormalities that exist at baseline before investigating any results from an activation or stimulation paradigm (Wang et al. 2013).

There are two primary methods for examining resting EEG recordings. First is by visual inspection of the record performed by an EEG expert. For the purposes of this review, we will use the term standard-EEG to refer to this methodology. Standard-EEG is capable of detecting significant generalized or focal slowing of the wakeful frequencies as well as detecting any form of paroxysmal or epileptiform activity. While focal and diffuse slowing of the EEG can be detected by the second methodology to interpret EEGs, namely the computer-analyzed reading of the EEG (C-EEG), standard-EEG is a much more widely available technique and costs less overall for processing and interpretation. Also, standard EEG remains the only reliable technique for detecting paroxysmal or epileptiform activity particularly when the epileptic discharges are either infrequent or low in amplitudes. Rapidly advancing computer capabilities allow not only an increase in the number of recording sensors (electrodes) from the standard 21 to as many as $\mathbf{2 5 6}$ or more but also an ever increasing level of sophistication in analyzing the data. Among recent advances in C-EEG signal processing are the ability to assess the topography of any detected change (mapping), assess the deeper cerebral sources of detected abnormalities (source localization), and examine the linearity and non-linearity of the recorded signal (complexity analysis). An important EEG attribute that can only be accessed via advancing computer technology is characterizing the functional connectivity among cortical regions. There are currently several methods to measure functional connectivity such as linear methods (correlation or coherence) and non linear methods (mutual information, entropy or phase synchrony). Of these, coherence, a measure of synchrony between signals from different regions for each frequency of the EEG signal, is currently the mainstay for assessing the similarity of signals recorded in 2 EEG electrodes. C-EEG also allows for the registration of the EEG signal conjointly with structural or functional imaging studies (MRI or fMRI) (i.e., multimodal registration). In this review, we summarize the published findings based on both standard EEG and C-EEG methodologies and present an overall view of what the data have revealed thus far about ASD as well as possible future research directions using these methodologies. 
To our knowledge, the current review is the first to synthesize reports of abnormalities in both standard and quantitative EEG literatures in an attempt to understand the neuropathophysiology of ASD. It should be emphasized that a complete understanding of this complex and heterogeneous group of disorders will require the eventual integration of data gleaned from all available observations including clinical, genetic, electrophysiological, neuroimaging and neuropharmacological studies.

\section{Review}

Methods

The purpose of the search was to identify peer-reviewed, full-length reports examining EEG deviations in children or adults with ASD. As expected, the majority of studies were conducted in children. For the purposes of this review, studies can be assumed to be related to children and adolescents unless otherwise specified, as studies in adults were not excluded. Papers examining the standard or C-EEG in ASD individuals who were not diagnosed with epilepsy constituted the focus of the search. Extensive searches of PubMed and Google Scholar were conducted using the following terms: autism, Autistic Disorders, Asperger's Disorder, Rett's Disorder, Childhood Disintegrative Disorder, and Pervasive Developmental Disorder Not Otherwise Specified (NOS) and EEG. The search was first limited by two main terms: English and Human. A total of 500 entries were returned. Titles of articles and abstracts, if necessary, were reviewed to judge if the report should be included. Majority of reports pertained to investigations of epilepsy in ASD, evoked potentials, quantitative EEG studies, neurofeedback and other treatment modalities, and tuberous sclerosis. All papers not addressing either abnormalities in the standard EEG or the quantified EEG were excluded. Papers including only epileptic patients were also excluded. Review articles were utilized as sources for additional papers and as sources for proposed hypotheses. A total of 20 reports addressed the prevalence of IEDs in non-epileptic ASD individuals as detected by the standard-EEG. One paper had two distinct ASD samples (children with and without regression), and the two samples were entered in Table 1 as two studies (Ošlejšková et al. 2008). Papers were then reviewed for sample size, characteristics of subjects, EEG methodology, prevalence of IEDs, and location of IEDs, if reported. The included 21 studies either reported the percent of records with IEDs in non-epileptic subjects or that percentage was calculable based on information provided. Twenty-two papers were identified addressing C-EEG in ASD. C-EEG papers were similarly reviewed for sample size, characteristics of subjects, EEG methodology, and reported deviations. Additional searches of Google Scholar did not yield additional reports.

\section{Results}

\section{Standard EEG abnormalities in non-epileptic ASD individuals: (Table 1)}

It is important to preface the following discussion of findings of epileptiform discharges in individuals with ASD by noting that such abnormal activity, in some cases, may only be detected during sleep and at times may require prolonged monitoring which may contribute significantly to exaggerated false negative rates of EEGs in any population examined. To illustrate current estimated rates of epileptiform activity in non-epileptic 
Table 1 Percentages of IEDs among non-epileptic ASD children

\begin{tabular}{|c|c|c|c|c|c|}
\hline Paper & $\mathbf{N}$ & $\begin{array}{l}\% \text { of subjects } \\
\text { with IEDs }\end{array}$ & Location & $\begin{array}{l}\text { Epilepsy } \\
\text { excluded* }\end{array}$ & Comments \\
\hline Small, 1975 & 147 & $\begin{array}{l}64 \text { (included } \\
\text { an unspecified } \\
\text { low\% of slow } \\
\text { wave abnormalities) }\end{array}$ & $\begin{array}{l}\text { Mainly focal and seen } \\
\text { in all locations. }\end{array}$ & Yes & $\begin{array}{l}\text { A single recording } \\
\text { yielded } 40 \% \\
\text { abnormalities, } 2 \\
\text { studies } 60 \% \text { and } 3 \\
\text { studies } 80 \% \text {. }\end{array}$ \\
\hline $\begin{array}{l}\text { Gillberg et al., } \\
1987\end{array}$ & 15 & 27 & & Yes & $\begin{array}{l}\text { Five additional } \\
\text { children with ASD } \\
\text { and epilepsy all } \\
\text { had abnormal } \\
\text { EEGs. }\end{array}$ \\
\hline $\begin{array}{l}\text { Rossi et al., } \\
1995\end{array}$ & 81 & $25 \%$ & $\begin{array}{l}\text { Focal and multifocal. } \\
45 \% \text { centro-temporal. }\end{array}$ & Yes & $\begin{array}{l}\text { Photoparoxysmal } \\
\text { response in some } \\
\text { children. }\end{array}$ \\
\hline $\begin{array}{l}\text { Tuchman \& } \\
\text { Rapin } 1997\end{array}$ & 335 & $8 \%$ & $50 \%$ centro-temporal & Yes & $\begin{array}{l}14 \% \text { in non- } \\
\text { epileptics but with } \\
\text { history of } \\
\text { deterioration. }\end{array}$ \\
\hline $\begin{array}{l}\text { Kawasaki } \\
\text { et al., } 1997\end{array}$ & 96 & 31.3 & Frontal & Yes & $\begin{array}{l}\text { A control group } \\
\text { with intellectual } \\
\text { development } \\
\text { delay and } \\
\text { exhibiting IEDs, } \\
\text { had very } \\
\text { significantly less } \\
\text { frontal lobe } \\
\text { discharges. }\end{array}$ \\
\hline \multirow[t]{3}{*}{ Lewine 1999} & 18, EEG & 22 & \multirow{3}{*}{$\begin{array}{l}\text { Paroxysmal MEG } \\
\text { activity mainly deep } \\
\text { into sylvian plane. }\end{array}$} & \multirow[t]{3}{*}{ Yes } & \multirow{3}{*}{$\begin{array}{l}\text { All children with } \\
\text { evidence of } \\
\text { regression. Notice } \\
\text { the progression in } \\
\text { yield from } \\
\text { standard EEG to } \\
24 \text { hour EEGs to } \\
\text { MEG. }\end{array}$} \\
\hline & 14, 24 h EEGs & 64 & & & \\
\hline & 35 MEG & 97 & & & \\
\hline $\begin{array}{l}\text { Hashimoto } \\
\text { et al., } 2001\end{array}$ & 68 & $54 \%$ & $76.6 \%$ frontal & Yes & $\begin{array}{l}\text { Additional ASD } 18 \\
\text { subjects with } \\
\text { epilepsy had a rate } \\
\text { of paroxysmal } \\
\text { discharges of } 72 \% \text {. }\end{array}$ \\
\hline $\begin{array}{l}\text { Hrdlicka et al. } \\
2004\end{array}$ & 50 & $15 \%$ & & Yes & $\begin{array}{l}\text { An additional } 9 \% \\
\text { of non-epileptic } \\
\text { ASD children had } \\
\text { non-paroxysmal } \\
\text { EEG abnormalities. } \\
\text { nWhen subjects } \\
\text { were classified into } \\
\text { those with and } \\
\text { without regression, } \\
\text { rate of paroxysmal } \\
\text { EEg abnormality } \\
\text { rose to } 44 \% \text {. }\end{array}$ \\
\hline $\begin{array}{l}\text { Reinhold } \\
\text { et al., } 2005\end{array}$ & $\begin{array}{l}316 \\
\text { (overnight } \\
\text { EEG } \\
\text { monitoring) }\end{array}$ & $26.8 \%$ & $\begin{array}{l}\text { Temporal (38\%), } \\
\text { frontal }(28 \%) \text {, central } \\
(23 \%) \text {, occipital }(8 \%) \text {. }\end{array}$ & Yes & $\begin{array}{l}\text { EEG monitoring } \\
\text { recommended } \\
\text { for ASD work-up } \\
\text { and more so if } \\
\text { regression is seen. }\end{array}$ \\
\hline $\begin{array}{l}\text { Gabis et al., } \\
2005\end{array}$ & 40 & 3.6 & & Yes & $\begin{array}{l}\text { Lowest rate } \\
\text { reported. No } \\
\text { obvious difference } \\
\text { either in the study } \\
\text { population or EEG } \\
\text { procedure used. }\end{array}$ \\
\hline
\end{tabular}


Table 1 Percentages of IEDs among non-epileptic ASD children (Continued)

\begin{tabular}{|c|c|c|c|c|c|}
\hline $\begin{array}{l}\text { Canitano } \\
\text { et al., } 2005\end{array}$ & 40 & $25 \%$ & $\begin{array}{l}\text { Mostly focal but few } \\
\text { multifocal. }\end{array}$ & Yes & \\
\hline $\begin{array}{l}\text { Hughes \& } \\
\text { Melyn, } 2005\end{array}$ & 32 & $19 \%$ & $\begin{array}{l}21 \% \text { had bilateral } \\
\text { spike discharges. }\end{array}$ & Yes & \\
\hline $\begin{array}{l}\text { Chez et al., } \\
2006\end{array}$ & $\begin{array}{l}889 \text { Overnight } \\
\text { (at least } \\
6 \text { hours) EEGs. }\end{array}$ & $60.7 \%$ & $\begin{array}{l}\text { Right Frontal }(21.5 \%) \text {, } \\
\text { Bitemporal }(20.2 \%) \text {. } \\
\text { Gen sp\& wave } \\
(16.2 \%) \text {, left temp } \\
(15.2 \%) .\end{array}$ & $\begin{array}{l}\text { Yes and } \\
\text { unmedicated } \\
\text { at times of } \\
\text { EEGs. }\end{array}$ & $\begin{array}{l}\text { No difference in } \\
\text { rate of EEG } \\
\text { abnormality } \\
\text { between those } \\
\text { with and without } \\
\text { regression. All } \\
\text { paroxysmal activity } \\
\text { were recorded } \\
\text { only during sleep. } \\
\text { Of } 176 \text { patients } \\
\text { with paroxysmal } \\
\text { activity and treated } \\
\text { with valproic acid } \\
\text { rate of EEG } \\
\text { abnormalities } \\
\text { decreased to } 36 \% \\
\text { with follow-up } \\
\text { EEGs. }\end{array}$ \\
\hline Hara, 2007 & 97 & $21 \%$ & $\begin{array}{l}\text { Mainly temporal but } \\
\text { also central/parietal. A } \\
\text { minority had focal foci. }\end{array}$ & Yes & $\begin{array}{l}\text { Epileptiform EEGs } \\
\text { predicted } \\
\text { subsequent } \\
\text { seizures. }\end{array}$ \\
\hline $\begin{array}{l}\text { Ošlejšková } \\
\text { et al., } 2008\end{array}$ & 57 & 42.5 & $\begin{array}{l}\text { Abnormalities were } \\
\text { mainly focal but specific } \\
\text { locations not reported }\end{array}$ & Yes & $\begin{array}{l}\text { Children with no } \\
\text { evidence of } \\
\text { regression }\end{array}$ \\
\hline $\begin{array}{l}\text { Ošlejšková } \\
\text { et al., } 2008\end{array}$ & 41 & 57.8 & & & $\begin{array}{l}\text { Children with } \\
\text { history of regression }\end{array}$ \\
\hline $\begin{array}{l}\text { Ünal et al., } \\
2009\end{array}$ & 81 & 27.2 & $\begin{array}{l}\text { Mainly temporal } \\
\text { regions }\end{array}$ & Yes & $\begin{array}{l}\text { Only } 8.3 \% \text { of } \\
\text { children without } \\
\text { evidence of } \\
\text { impaired intellectual } \\
\text { development had } \\
\text { abnormal EEGs. }\end{array}$ \\
\hline $\begin{array}{l}\text { Hartley- } \\
\text { McAndrew } \\
\text { and weinstock, } \\
2010\end{array}$ & 15 & 33 & $\begin{array}{l}\text { Focal spike and wave } \\
\text { complexes, different } \\
\text { locations. }\end{array}$ & Yes & $\begin{array}{l}\text { Six additional ASD } \\
\text { children had } \\
\text { history of seizures } \\
\text { and } 83 \% \\
\text { abnormalities. The } \\
\text { study suggest that } \\
\text { in the absence of } \\
\text { fraak epilepsy, } \\
\text { signs like starring, } \\
\text { automatism or } \\
\text { shaking episodes } \\
\text { are not good } \\
\text { predictors of } \\
\text { abnormal EEGs. }\end{array}$ \\
\hline $\begin{array}{l}\text { Parmeggiani } \\
\text { et al., } 2010\end{array}$ & 259 & $31 \%$ & $\begin{array}{l}\text { Temporal and central } \\
31.4 \% \text {. Much less } \\
\text { frontal. }\end{array}$ & Yes & $\begin{array}{l}\text { Seizures and EEG } \\
\text { PA were not } \\
\text { related to autistic } \\
\text { regression. }\end{array}$ \\
\hline $\begin{array}{l}\text { Ekinci et al., } \\
2010\end{array}$ & 51 & $8 \%$ & & Yes & $\begin{array}{l}\text { No relation } \\
\text { between severity } \\
\text { of intellectual } \\
\text { dysfunction and } \\
\text { presence of IEDs }\end{array}$ \\
\hline
\end{tabular}


Table 1 Percentages of IEDs among non-epileptic ASD children (Continued)

\begin{tabular}{|c|c|c|c|c|c|}
\hline $\begin{array}{l}\text { Kanemura } \\
\text { et al., } 2013\end{array}$ & 21 & $50 \%$ & $\begin{array}{l}\text { Frontal, central and } \\
\text { temporal. }\end{array}$ & Yes & $\begin{array}{l}\text { The presence of } \\
\text { frontal paroxysms } \\
\text { was significantly } \\
\text { associated with } \\
\text { later development } \\
\text { of epilepsy } \\
\text { compared with } \\
\text { centrotemporal } \\
\text { paroxysmus }\end{array}$ \\
\hline
\end{tabular}

* It was possible to decide the number of ASD subjects with no history of epilepsy and the prevalence of paroxysmal EEG abnormalities in this sample.

individuals with ASD, Table 1 lists the percentages of reported abnormal EEGs among non-epileptic children with ASD.

In a study by Small (1975), epilepsy was exclusionary but some participants did go on to later develop epilepsy. A single recording showed abnormalities in $40 \%$, two recordings showed abnormalities in 60\%, and three recordings showed abnormalities in $80 \%$ of participants, highlighting the importance of prolonged or repeated monitoring to detect infrequent epileptiform discharges.

Tuchman \& Rapin (1997) examined the EEGs (containing sleep) of 392 children on the autism spectrum with or without histories of epilepsy. The EEGs were epileptiform in $59 \%$ of ASD children with histories of epilepsy but only in $8 \%$ of 335 children without history of seizures. When historical clinical deterioration was evident (as was the case in 155 non-epileptic children), the rate of epileptiform EEG abnormalities was significantly higher (14\%) compared to the rate in children without obvious deterioration (6\%). Importantly, the authors note that the average child was first evaluated neurologically four years following the onset of deterioration. This review proposes that epileptiform activity may not be completely benign and the value of early detection and perhaps treatment needs further investigation.

Hashimoto et al. (2001) examined the EEGs (during sleep) of 86 children with ASD. Forty-three percent (37 cases) had epileptic discharges. Of these 37 patients, 27 (73\%) had localized spikes, eight had multiple spike foci, one had generalized spikes and one had both focal and generalized spikes. Forty-seven epileptic discharging foci were identified in the 36 patients with focal abnormalities. Thirty-six (76.6\%) of these foci were in the frontal region, one in the temporal, 7 in the centro-parietal, and 3 in the occipital regions. These results are consistent with the hypothesis that frontal dysfunction may be important in the development of autistic symptoms.

Chez et al. (2006) reviewed the EEGs of a large number of children with ASD for the purpose of providing a definite account of the rate and nature of EEG abnormalities in children with autistic symptoms who had no seizures or identifiable genetic problems. Starting with 1,268 children with ASD examined between 1996 and 2005, they excluded children with identified genetic disorders, tuberous sclerosis, or history of seizures. The remaining 889 children with no prior evidence of epilepsy underwent 16-channel ambulatory sleep EEGs revealing EEG abnormalities in 60.7\%. One of the most important findings of this investigation was that, in this population, epileptiform abnormalities were detected only during sleep. A second important finding is the report of different forms of epileptic activities with focal temporal regions being the most common next to generalized spike and slow wave discharges. As is well known, the pathophysiologies 
of these abnormal discharges are different. This suggests the possibility that within the group of non-epileptic children with ASD with epileptic discharges, more specific phenotypes may exist. Canitano and Zappella (2006) suggested the term Autistic Epileptiform Regression for non epileptic autistic children with epileptiform EEGs. Moreover, in this rather large sample, the frequency of frontal lobe epileptic activity was rather low. This observation requires replication, as it has been suggested that involvement of the frontal lobes may be important for the eventual development of ASD symptoms. Finally, 176 of the patients with epileptic discharges were placed on valproic acid for treatment. In follow up EEGs (on average 10 months later), 46.6\% normalized, and an additional $17 \%$ showed improvement. None had worsened. It should be noted that this investigation only included retrospective reviews of the EEGs and clinical correlations were not reported. The authors concluded that a more proactive approach to evaluation and treatment was justified as some of the physiological abnormalities may be reversible. This conclusion is supported by the work of Pressler et al. (2005) in which they show that treatment of interictal epileptiform discharges can improve behavior in epileptic children with behavioral problems.

In an effort to develop guidelines for screening EEGs in ASD, Kagan-Kushnir et al. (2005) conducted a comprehensive review of the then available literature. They concluded that seizures are common in ASD, occurring in $20-30 \%$ of children with this disorder based on the majority of studies available at the time. Subclinical EEG abnormalities (i.e., no epilepsy) were found in 6.1 to 31\%. Evidence for the effectiveness of anticonvulsants and corticosteroids in reducing seizures and/or autistic symptoms was based primarily on case series. They concluded that as of the time of the publication there was insufficient evidence to recommend against the use of screening EEGs in patients with ASD. This conclusion remains consistent with currently available evidence. A proposed direction for future investigations was to identify a level of functioning above which screening EEGs are consistently normal. The authors also concluded that given the high frequency of seizure disorders in this population, a high level of clinical vigilance should be maintained for subtle symptoms of seizures.

Frye et al. (2010) retrospectively reviewed the charts of 22 children with atypical cognitive development that did not respond to standard educational therapy and demonstrated discharges on EEG. Only 9\% of the sample had a history of seizures but the majority of children had multifocal discharges on the EEGs. Of the 20 patients subsequently treated with antiepileptic medications, 70\% demonstrated definite improvement within one clinic visit. The study suggests that children with EEG discharges and developmental cognitive disorders demonstrate an identifiable pattern of symptomatology and discharges on EEG that respond well to anti-epileptic drug (AED) treatment. This study also demonstrated that monitoring in an epilepsy monitoring unit is significantly superior to standard out patient EEGs in detecting paroxysmal discharges.

\section{Electrical Status Epilepticus in Slow-wave Sleep (ESES)}

ESES is an epileptic syndrome that occurs in childhood and typically presents with seizures, significant EEG abnormalities and cognitive dysfunction (Sanchez-Fernandez et al., 2013), and was originally described by Patry et al. (1971). The EEG is characterized by continuous slow spike-wave activity during non-REM sleep. Cases of ESES without frank epilepsy have also been reported (Sanchez-Fernandez, et al., 2012). It 
occurs in children (mostly around the age of eight years) with chiefly nocturnal seizures and mild mental retardation. The unique EEG manifestations during non-REM sleep are coupled with rather minimal EEG abnormalities during wakefulness, perhaps accounting for what is possibly a lower rate of recognition. The dramatic changes during sleep disappear during adolescence. It is important to note that when a child with ESES is awakened from such a severely disturbed sleep, he/she is usually fully alert and with no obvious signs of cognitive problems. Deterioration of language and behavior are also seen in this condition and may range from a severe global deterioration compatible with the diagnosis of disintegrative disorder or ASD to minimal or absent behavioral correlates (Rapin 1995).

Larsson et al. (2012) provided evidence from a placebo-controlled double-blind cross-over study that antiepileptic drugs (in this case levetiracetam) can significantly decrease the frequency of epileptic discharges in these individuals irrespective of whether or not they have manifest epilepsy. Subsequently, the same group (Bjørnæs et al. 2013) reported on the correlation between spike activity during sleep and when awake on learning, long-term memory and vigilance before and after treatment with levetiracetam in these children with ESES. Of the 23 children included, 17 had no history of epilepsy but were diagnosed with either attention deficit hyperactivity disorder (ADHD) or Asperger's Syndrome. The study included an eight-week treatment phase and four-weeks for titrating upward and gradual discontinuation. At baseline, verbal learning (i.e., number of words recalled in best trial during acquisition) was lower in individuals with higher levels of spike activity. Similarly, poorer verbal and design recall the following morning were associated with increased spike activity. On the other hand, there were no relationships between spike activity and indices of consolidation (percent of learned material remembered the following morning) except for designs. Despite the fact that levetiracetam was effective in reducing sleep-related spike activity, on the group level, levetiracetam had no clear effects on behavior, vigilance or learning and memory in these children. The authors concluded that these results did not allow firm conclusions regarding treatment of nocturnal epileptiform activity when associated with autistic like symptoms; larger samples and longer follow-up may be needed in order to firmly answer this important question.

\section{Discussion, conclusions and questioned raised from standard-EEG studies of ASD}

There is ample data supporting the observation that the rate of epilepsy among children with ASD is significantly elevated when compared to other psychiatric disorders (Valvo et al. 2013). It is also well-supported that a significant percentage of non-epileptic children with ASD exhibit IEDs and that a large proportion of children with ASD with abnormal EEGs are unlikely to develop a seizure disorder. Table 1 gives a wide range of the reported prevalence of IEDs in this population suggesting that many variables may be contributing to the noted variance among studies. In addition to the acknowledged heterogeneity, symptom severity, age, presence of intellectual disability, as well as recording and analysis techniques utilized, possible issues with interrater reliability may have further contributed to the variability in findings (Gilbert, 2006). Chez et al. (2004) reported the rate of IEDs in non-epileptic non-ASD sibs of children with ASD to be much lower and, even when present, was of a different nature suggesting that genetic factors may not be high on this list of variables. Longitudinal studies may be necessary to clarify whether and how 
bioelectrical abnormalities play a causal role in those subgroups of children with various degrees of both language deterioration and autistic symptoms. The presence of epileptic discharges in non-epileptic ASD patients could represent an endophenotype that may have treatment and prognostic implications as well as helping to decrease the heterogeneity of the disorder in study samples. Available literature also raises a number of additional questions that seem to be quite amenable to examination in well-designed research studies. First, the cost effectiveness of EEG work-up in children exhibiting ASD symptoms has not been determined. Of course, if intervention at some stage can prevent or ameliorate a life-long disorder, even a low yield may be well justified not only on economic bases but also for the suffering of patients and their families that may be avoided. Does the fact that an epileptic discharge was not detected via EEG or magnetoencephalography (MEG) technologies necessarily mean that there is no such activity going on? Data provided by Small (1975) and Frye et al. (2010) suggest that multiple EEG studies will lead to an increased yield with the best yield obtained from epilepsy monitoring units (Frye et al. 2010). Recording of EEGs and MEGs suggest that MEG may detect IEDs when EEG fails to detect them. A study that utilized MEG (Lewine 1999) to compare patients with LKS and ASD identified epileptiform activity in 41 of 50 ASD patients (82\%) while simultaneous EEG revealed epileptiform activity in only $68 \%$. This is an important observation as it highlights the fact that a negative test does not mean the absence of abnormality, thus underscoring the significant false negative problem, particularly with EEG studies. Another rather important and as yet uninvestigated question is how the presence of IEDs affects neural development in non-epileptic children with ASD. Does the location of the IED have a bearing on clinical symptomatology? A study by Hashimoto et al. (2001) suggests that the presence of both frontal and temporal abnormalities may be important for the emergence of autistic symptoms. Kayaalp et al. (2007) examined a group of children with West Syndrome (infantile spasms with severe EEG abnormalities) and compared the rate of emergence of autistic features to the nature of EEG abnormalities (two groups were formed; West with autism and West without autism). The number of patients with at least one hypsarrhythmic EEG at age one year or later was significantly higher in the ASD group (86\%) than in the non-ASD group (29\%). Frontal predominance of the primary foci on EEGs with and without hypsarrhythmia was seen in $95.3 \%$ of the ASD group but only $28.8 \%$ of the non-ASD group. The authors suggest that paroxysmal discharges in cortical areas undergoing rapid maturation may be involved in the development of autistic features. Finally, what are the clinical implications of detecting IEDs in a non-epileptic individual with ASD, in terms of how it might inform treatment? And how would the timing of the initiation of an AED affect the clinical response?

It should be noted that the above summarized literature spans a 40 year period during which diagnostic criteria of autism and ASD varied. It is difficult to determine the impact that this variation may have had on the issues being addressed in this review, highlighting the importance of precise characterization of study samples in future research on EEG abnormalities in ASD.

\section{Computer-analyzed EEG (C-EEG) Introduction to C-EEG}

As mentioned above, C-EEG is a rapidly growing discipline. Given its high sensitivity to small variations in activity compared to standard-EEG, it is very likely that studies 
utilizing any C-EEG based technique will detect many and varied abnormalities in this patient population. ASD are behavioral syndromes undoubtedly caused by complex genetic and non-genetic risk factors. It has been proposed that these risk factors lead to alterations in the development and 'wiring' of brain circuits and hence, the emergence of ASD. C-EEG as well as MEG (which is covered by a previous review from the same group; Lajiness-O'Neill et al. 2014) is quite suitable for probing these functional physiological alterations. The above combined with the significant heterogeneity and likely a high degree of complexity of the disorder makes for the inevitable generation of a large number of findings that may vary between studies and may not be easily replicated. Computer-based analysis of EEG recordings allow for an ever-expanding repertoire of computational analytic methodologies, adding to the variability in reported results and further hindering the field's ability to arrive at consistent findings. A good example is provided by Pop-Jordanova et al. (2010), who introduced the calculation of "spectrum weighted frequency" and introduced the term "brain rate" which reflected an EEG spectrum-weighted frequency. Not much later Sheikhani et al. (2012) differentiated between spectral analysis and spectrogram criteria. Details of their analysis procedure were provided to facilitate replication attempts (Sheikhani et al. 2012). It may be necessary for this line of investigation to follow a proscribed and systematic progression of EEG findings to eventually lead to clinical usefulness (Arfken et al. 2009; 2014). It is presumed that a robust biological finding can be identified by various independent groups and its ability to differentiate a particular target patient population from either non-patients or other patients with disorders commonly appearing on the same differential diagnostic list (Boutros et al., 2014). Hence, the purpose of the current review is to highlight any findings that seem to have some level of consistency (Webb et al. 2013) and any possible links to abnormalities reported using standard EEG methodology.

\section{C-EEG has the potential to illuminate some of the hypothesized subtypes within the ASD spectrum}

Heterogeneity of ASD is widely accepted. One of the best established, albeit rare, causes of ASD is the genetic condition Tuberous Sclerosis Complex (TSC); 40\% of individuals with this condition develop ASD. The locations of tuberous sclerosis (TS) lesions can be identified via imaging, and hence it is possible to study the development of autistic like symptoms in relation to the anatomical locations of the lesions. Peters et al. (2013) examined the TS model to understand the neuropathology underlying autistic development. Brain functional networks of EEG connectivity were studied in patients with TSC as well as in patients with ASD without TSC to examine the differences in network properties between these groups (Peters et al. 2013). EEG connectivity was characterized by the mean coherence, the ratio of inter-over intra-hemispheric coherence and also the ratio of long- over short-range coherence. In ASD, both with and without a concurrent diagnosis of TSC, decreased long- over short-range coherence ratios were found in all frequency bands. It should be noted that while the ratio of long- to shortterm coherence was decreased, the mean coherence values (taking into account both long and short distance coherences) were not significantly different from healthy control subjects. Thus it could be concluded that the decreased ratio indicates local overconnectivity accompanied by a proportional long-range under-connectivity in patients 
with ASD. The authors concluded that the data provide further support for "miswired" neural circuitry in ASD (Peters et al. 2013). This study suggests that the presence of TSC is not sufficient to induce autistic like symptoms but that a particular pattern of distribution of the lesions resulting in disruption of both long and short distance coherence may be necessary for such symptoms to emerge. As suggested by Hashimoto et al. (2001), it may be crucial that both frontal and temporal regions be affected for the pattern of behavior to actually materialize.

Duffy et al. (2013) explored the relationship between Asperger's Syndrome (ASP) and individuals with Autistic Disorder (AD). To date, no clear biomarkers have reliably distinguished ASP and AD populations. This study used EEG coherence as a measure of brain connectivity to define any possible neurophysiological differences between the two conditions. Using EEG coherence, 92.3\% ASP subjects were identified as separate from the $\mathrm{AD}$ population. By contrast, five randomly selected subsamples of $\mathrm{AD}$ subjects failed to be differentiated when compared to the remaining AD populations suggesting that the variance within the $\mathrm{AD}$ group is significantly less than the variance between the AD and the ASP groups. Within a control-AD dichotomy, an ASP population falls closer to AD than controls. However, when compared directly with AD, an ASP population is distinctly separate. The interested reader is urged to review these studies for important methodological details (Duffy et al. 2013). These results suggest that C-EEG-based measures may be useful in decreasing the heterogeneity within ASD study samples, perhaps eliminating some of the sources of variance in the literature.

\section{Resting State EEG Studies}

It should be stated at the outset that the majority of C-EEG studies of ASD excluded epilepsy but only rarely were the presence of IEDs assessed. One of the earliest studies examining resting EEG in the ASD population compared to appropriate controls was reported by Cantor et al. (1986). Low-functioning children with autism, age-matched neurotypicals (NT), age-matched intellectually disabled, and mentally age-matched neurotypical toddlers were tested. The children with autism showed significantly more slow wave activity and less alpha $(\sim 8-13 \mathrm{~Hz})$, as well as less inter- and intrahemispheric asymmetry than either typically developing children or children with intellectual disability. The authors proposed a model of diminished cortical differentiation to account for the low level of intellectual functioning. Later studies supported the findings of significantly higher absolute delta $(\sim 1-4 \mathrm{~Hz})$ activity while relative alpha activity was decreased (Chan et al. 2007).

While Hashimoto et al. (2001), based on standard EEG findings, suggested that the involvement of the frontal lobes may be important for the emergence of autistic symptoms, the emergence of the computer-based capabilities allowed examination of data to add further support to this notion. Murias et al. (2007), utilizing narrow frequency bands to examine functional connectivity (i.e., EEG coherence) in 18 adults with ASD and 18 matched healthy control subjects, made a number of important observations. They reported locally elevated coherence in the theta range in the ASD group particularly in the left frontal and temporal regions. They also reported more widespread reduced coherence but particularly within the frontal region and between frontal and other cortical regions in the lower alpha range $(8-10 \mathrm{~Hz})$. They also found support for an increase in delta/theta power in ASD. 
Sheikhani et al. (2012) found a significant decrease of alpha activity in a group of children with ASD in the left frontal and temporal regions using a short-time Fourier transform (a form of Fast Fourier transform; see Sheikhani et al. 2012 for technical details). Based on the alpha differences, ASD could be differentiated from control subjects with 96.4\% accuracy. In this report, Sheikhani et al. (2012) point to the preponderance of coherence abnormalities in the higher frequency ranges. Stroganova et al. (2007) examined the EEGs of 44 boys with autism and equal number of control subjects from two independent centers and reported a higher amount of delta activity in the prefrontal region. An abnormal broadband leftward asymmetry was noted primarily in the temporal region. This deviation was suggested to reflect a diminished capacity of the right temporal cortex to generate EEG rhythms. Coben et al. (2008) examined absolute, relative, and total power as well as inter- and intrahemspheric coherence in high functioning children with ASD and matched healthy controls. They observed excessive theta, primarily in right posterior regions, with deficient delta in the frontal cortex in ASD. Moreover, there was a pattern of under connectivity associated with ASD. Pop-Jordanova et al. (2010) reported increased delta/theta activity in the frontal lobes of children with ASD. Adding another level of complexity to this literature, Daoust et al. (2004) examined the spectral power in individuals with ASD (adults and children) during REM sleep, evening wakefulness and morning wakefulness. They reported that persons with ASD had significantly lower absolute beta over the occipital regions during REM sleep and significantly higher absolute theta over the left frontal pole region during evening wakefulness but not during morning wakefulness.

Resting anterior EEG asymmetry has been proposed to be a measure reflecting complex brain processes associated with individual differences in approach and avoidance motivation (Sutton et al., 2005). Sutton et al. (2005) reported that resting anterior EEG asymmetry, may help explain differences in the expression of autism in children without intellectual disabilities. Burnette et al. (2011) reported that only higher functioning children with ASD (HFA) with IQs above 70 and who exhibited a pattern of left frontal EEG asymmetry tended to display milder symptoms of social impairment. Left frontal EEG asymmetry was also associated with retrospective parent reports of significantly later age of onset of symptoms, but also higher levels of self-reported outward expressions of anger as well as symptoms of obsessive compulsive disorder in school-age higher functioning children with ASD. The authors of the report concluded that individual differences in anterior EEG asymmetry may significantly moderate the expression and developmental course of autism and thus may have clinical implications for identifying meaningful diagnostic sub-groups among children with autism.

Duffy and Als (2012) examined EEG coherence in 463 ASD children and 571 neurotypical control (NT) children (ages from 1 to 18 years). Coherence measures demonstrated reduced short-range coherence but a more complex picture for long-range coherence (i.e., increased long-range coherence between some regions and decreased long-range coherence between other regions) for the ASD-group when compared to the controls. This study has further implications as predominantly reduced short-range coherence may indicate poor local network function, while increased long-range coherences may represent compensatory processes (Duffy \& Als 2012). It should be noted 
that the findings of decreased short-range coherence and increased long-range coherence are at variance with a significant portion of this literature, underlining the issue of heterogeneity in this population as well as the possible influence of methodology utilized on the findings.

Mathewson et al. (2012), targeting adults with ASD, examined regional eyes-closed and eyes-open EEG alpha power and coherence at rest in relation to self-reported perceptual and social behavior in ASD $(\mathrm{N}=15)$ and a matched healthy control group $(\mathrm{N}=16)$. The groups did not differ on eyes-closed EEG alpha power or coherence, but adults with ASD showed less alpha suppression for the eyes-open condition than did controls. In the ASD group, preferential attention to detail (perceptual domain) was associated with lower levels of alpha activity and reduced coherence in posterior regions. The investigators found no relationships between social interaction difficulties (social domain) and alpha measures in either group and concluded that these relationships suggest that the processing of perceptual details may be carried out by relatively less synchronized neuronal units in adults with ASD, and may be relatively automatic (Mathewson et al. 2012). These data are consistent with MEG data reported by Falter et al. (2013).

Maxwell et al. (2013) explored resting gamma power $(\sim 30-80 \mathrm{~Hz})$ across multiple brain regions in this patient population using EEGs in 15 boys with ASD and 18 ageand IQ-matched NT controls. They found a decrease in resting gamma power at right lateral electrodes in ASD. They further explored associations between gamma and ASD severity as measured by the Social Responsiveness Scale (SRS) (Constantino 2002) and found a negative correlation between SRS total scores and gamma power and concluded that decreased gamma oscillations may be a potential biomarker for ASD.

The dimensional approach to ASD considers ASD as the extreme of a dimension encompassing the entire population. Based on this concept, Barttfeld et al. (2013) explored the potential utility of EEG functional connectivity as a biomarker and hypothesized that individual differences in autistic traits of NT subjects would involve a long-range connectivity diminution within the delta band. To test the above assumption they examined resting-state EEG functional connectivity of 74 NT subjects. All participants also provided the SRS questionnaire that was completed by an informant who knew the participant in social settings. The reported decrease in functional connectivity mainly within the delta and theta bands was associated with a higher number of autistic traits. They also observed that the optimal properties of functional networks were inversely related to the number of autistic traits, suggesting that the autistic dimension, throughout the entire population, modulates the efficiency of functional brain networks. They concluded that EEG functional connectivity at low frequencies and its associated network properties may be associated with some autistic traits in the general population (Barttfeld et al. 2013).

Catarino et al. (2013) tested the hypothesis of reduced interhemispheric coherence in ASD. This study analyzed EEG data from 15 participants with ASD and 15 typical controls to calculate interhemispheric coherence for EEG frequencies from 5 to $40 \mathrm{~Hz}$. Results demonstrate a reduction of interhemispheric coherence in the ASD group relative to the control group and for all electrode pairs studied (i.e., reduction in coherence is widely dispersed across the brain). Catarino et al. (2013) did not find significant differences in EEG power spectra between the groups. This is in contrast to Machado 
et al. (2013) who studied children with ASD using C-EEG spectral analysis during resting state as well as various task conditions and reported significant reductions for the absolute power spectral density (PSD) in the central region for delta and theta, and in the posterior region for the beta band, lateralized to the right hemisphere. Notably, the frequency range examined by Catarino et al. did not include the gamma frequency band, in which many previous investigations have found differences between ASD and neurotypicals.

Utilizing a novel methodology, Thatcher et al. (2009) used complex demodulation to compute instantaneous phase differences between electrodes sites and calculated phase shift duration and phase lock duration (reader advised to review the report for methodological details). They reported that phase shift duration was shorter in all frequency bands in ASD and specifically in the low alpha band $(8-10 \mathrm{~Hz})$.

\section{Premorbid markers}

Complex neurodevelopmental disorders may be characterized by subtle brain function signatures early in life before behavioral symptoms are apparent. Such endophenotypes may be measurable biomarkers for later cognitive impairments. Early detection of abnormalities in EEG signals may allow early intervention to prevent or ameliorate life long conditions. To our knowledge, there are no standard-EEG studies of infants who are considered to be at high risk for ASD.

Tierney et al. (2012) examined the hypothesis that ASD is characterized by asynchronous neural oscillations and explored whether changes in neural oscillations are specific to the disorder or are shared more broadly among both affected and unaffected family members. They further addressed how early these differences emerge in development and whether they remain constant or change over time. In this study the authors examined developmental trajectories of spectral power in infants at highor low-risk for ASD. Spectral power was extracted from resting EEG data recorded over the frontal regions when infants were 6, 9, 12, 18 and 24 months of age. They reported that across all bands, spectral power was lower in high-risk infants compared to low-risk infants at 6-months of age. Furthermore, high-risk infants showed different trajectories of change in spectral power in the subsequent developmental window indicating that not only are the patterns of change different, but that group differences are dynamic within the first two years of life (Tierney et al. 2012).

The nonlinear complexity of EEG signals is believed to contain information about the architecture of the neural networks in the brain on many scales. Bosl et al. (2011) suggested that the modified multiscale entropy (mMSE) computed on the basis of resting state EEG data may be a biomarker of normal brain development. Using mMSE as a feature vector, a multiclass support vector machine algorithm was used to classify typically developing and high-risk groups. Classification was computed separately within each age group as infants were tested at ages 6, 9, 12, 18 and 24 months. Multiscale entropy appeared to manifest in a different developmental trajectory in the infants at high risk for autism than it does in the typically developing controls with differences appearing to be greatest at ages 9 to 12 months. While independent replications are needed, these data suggest that mMSE computed from resting state EEG signals may be a useful biomarker for early detection of risk for ASD and abnormalities in cognitive development in infants (Bosl et al. 2011). 
One potential neural endophenotype of ASD is resting frontal EEG alpha asymmetry, a metric of hemispheric organization. Gabard-Durnam et al. (2013) examined the development of frontal EEG alpha asymmetry in ASD high-risk and low-risk infant populations. They reported that low and high-risk infants show different patterns of alpha asymmetry at 6 months of age and opposite growth trajectories in asymmetry over the following 12 months. In another study, the EEGs of 12 toddlers with ASD and 19 age-matched control subjects were used to assess interregional functional brain connectivity (Boersma et al. 2013). Children with ASD showed a pattern suggestive of a reduction in global communication capacity that was already evident during early brain development. Whole brain connectivity was found to be significantly reduced suggesting an overall under-connectivity of functional brain networks in ASD. Moreover, these findings further support the hypothesis of abnormal neural communication in ASD, with deviating effects already present at the early stages of brain development (Boersma et al. 2013). The absence of standard EEG studies in ASD high-risk infants is a glaring deficiency in this literature as it is completely unknown when IEDs manifest in ASD children who exhibit these discharges. It is also possible that some of the above biomarkers may indicate the need to closer monitoring of high-risk infants in order to detect early behavior or cognitive deviations or even development of IEDs. It is paramount, based on the above, that the effects of ameliorating these early deviations (including the emergence of IEDs) on the eventual development of ASD symptoms be fully explored.

\section{Conclusions from C-EEG}

In 2011, Wass reviewed the available literature and concluded that the bulk of the evidence supported significant connectivity disturbances in ASD that are possibly widespread with two specific aspects: over-connectivity in the local networks and under-connectivity in the long-distance networks (Wass 2011). Furthermore, the review suggested that disruptions appear more severe in later developing parts of the brain (e.g., prefrontal cortex). In fact, the idea that local and long-distance connectivity can be dysfunctional in different directions is quite plausible. Belmonte et al. (2004) suggested that abnormally increased physical connectivity (which is more prevalent in local neuronal groups) and abnormally decreased computational connectivity (which is more prevalent in long-distance connectivity) may reinforce each other by failing to differentiate signal from noise. Wass (2011) also noted that not every report uncovers the same finding, most likely pointing to the heterogeneity of the disorder and the methodologies utilized.

Wang et al. (2013) provided a more recent review of resting-state EEG of ASD children and concluded that available literature suggests a U-shaped profile of widely distributed electrophysiological power alterations, with excessive power in lowfrequency and high-frequency bands, abnormal functional connectivity, and enhanced power in the left hemisphere of the brain. Wang et al. (2013) suggested that abnormal functioning of the gamma- aminobutyric acid (GABA) in inhibitory circuits could result in an imbalance between inhibition and excitation in the brain and may at least be partially blamed for the widely noted dysfunctions. Similarly, Billeci et al. (2013) in a review concluded that ASD is associated with abnormalities in neural connectivity at both the global and local levels. They addressed the relevance of this approach in clustering phenotypes and concluded that the use of advanced techniques for increased 
specificity and improved spatial localization could enable the discovery of distinctive patterns of C-EEG abnormalities in ASD subjects. ASD patients with distinct C-EEG profiles may prove to respond differently to different treatment modalities and thus pave the way for the development of tailored intervention strategies. The ability to detect long-distance coherence and connectivity disturbances is an established technique. The more recent development of coherence source imaging (CSI) allows the identification of pockets of abnormally increased focal coherence (as contrasted to coherence assessed at surface electrode recording locations) and thus focal hyperexcitability (Boutros et al., 2013; Elisevich et al. 2011; Moran 2008; Moran et al. 2004, 2005). Hyperexcitable brain tissue is the characteristic of epileptogenic brain foci and recent advances from epilepsy research point to abnormally increased localized coherence within epileptic zones (Elisevich et al. 2011). To our knowledge CSI has not been applied to investigating ASD.

Webb et al. (2013) provided recent guidelines for conducting electrophysiological studies in ASD. They highlight the importance of taking developmental processes into consideration and having consistent methodological standards.

\section{Conclusions}

Aberrant brain connectivity patterns have indeed been hypothesized to be a key neural underpinning of the impaired social interactions and aberrant basic information processing characteristic of ASD. Because efficient communication and integration of information between brain regions play key roles in healthy brain function, disruptions in this communication may lead to cognitive and behavioral problems. As an inevitable product of the heterogeneity of ASD and the richness of the analysis techniques available to C-EEG investigators, a large range of findings are reported in association with ASD. Nonetheless, much of the available evidence points to the presence of hyperexcitable brain regions. These regions may be contributing to aberrant short and long distance connectivity and thus faulty working of neural modules essential for proper integration of information within the brain. The significant overlap between epilepsy and ASD was the basis for proposing a common pathophysiology between the two disorders (Gilby and O'Brien 2013). We here contend that the presence of multiple focal hyperexcitability loci in the brain could function as the basis for developing ASD, ASD co-morbid with epilepsy or epilepsy alone. Our prior work with an animal model of the isolated epileptic discharges (rats with epileptic discharges in the absence of epilepsy) showed that behavioral aberrations can be associated with such discharges (Barkmeier et al. 2012). This hyperexcitability may also help explain the frequent association between epilepsy, autism and hyperactivity (Barkmeier et al. 2012; Lo-Castro \& Curatolo 2013). We thus conclude by strongly suggesting that the presence of IEDs in non-epileptic individuals with ASD should be treated as a variant-covariant in electrophysiological studies. The same cannot be as positively stated for the absence of IEDs. Nonetheless, if adequate EEG work-up were performed (including awake and asleep EEGs, ambulatory EEG or MEG) with negative results, including an individual in a no-IED group would be justifiable by today's available technology.

Finally, it is not known whether currently available seizure medications are effective in normalizing hyperexcitable brain tissue that has not yet become capable of inducing seizures. Scattered reports suggest that a few of these medications may have some 
efficacy in this regards but further research is needed to examine these efficacies, particularly in newly diagnosed ASD patients (Boutros et al. 2014).

\section{Abbreviations}

AD: Autistic disorder; AED: Anti-epileptic drug; ASD: Autistic spectrum disorders; ASP: Asperger's syndrome; CSI: Coherence source imaging; EEG: Electroencephalogram; C-EEG: Computer-analyzed EEG; ESES: Electrical status epilepticus in slow-wave sleep; IEDs: Isolated epileptic discharges; LKS: Landau-Kleffner syndrome; MEG: Magnetoencephalogram; NT: Neurotypical; TSC: Tuberous sclerosis complex.

\section{Competing interest}

The authors declare that they have no competing interests.

\section{Authors' contribution}

NNB conceived of the purpose for the review and its direction and helped to draft the manuscript. RLO contributed to the thorough representation and interpretation of quantified EEG studies. AZ contributed to the thorough representation and interpretation of standard EEG studies. SB contributed to the development and organization of the manuscript. AR contributed to the development and organization of the manuscript. All authors contributed to revising the manuscript. All authors read and approved the final manuscript.

\section{Author details}

${ }^{1}$ Department of Psychiatry and Neurosciences, University of Missouri Kansas City, Center for Behavioral Medicine, 1000 E. 24th Street, Kansas City, MO 64108, USA. ²Department of Psychology, Eastern Michigan University, Ypsilanti, MI, USA. ${ }^{3}$ Department of Neurology, Henry Ford Hospital, Detroit, MI, USA. ${ }^{4}$ Department of Neurology, Wayne State University, Detroit, MI, USA. ${ }^{5}$ Department of Physics, Oakland University, Rochester, MI, USA.

Received: 26 June 2014 Accepted: 3 October 2014

Published online: 06 May 2015

\section{References}

Amiet C, Gourfinkel-An I, Bouzamondo A, Tordjman S, Baulac M, Lechat P, Mottron L, Cohen D (2008) Epilepsy in autism is associated with intellectual disability and gender: evidence from a meta-analysis. Biol Psychiatry 64 (7):577-82

Amiet C, Gourfinkel-An I, Laurent C, Carayol J, Génin B, Leguern E, Tordjman S, Cohen D (2013) Epilepsy in simplex autism pedigrees is much lower than the rate in multiplex autism pedigrees. Biol Psychiatry 74(3):e3-4, doi: 10.1016/j.biopsych.2013.01.037. Epub 2013 Mar 15

Arfken CL, Carney S, Boutros NN (2009) Translating biological parameters into clinically-useful diagnostic tests. Curr Psychiatry Rep 11:320-323

Arfken CL, Joseph A, Sandhu GR, Rhoers T, Douglass AB, Boutros NN (2014) The status of sleep abnormalities as a diagnostic test for major depressive disorder. J Affect Disord 156:36-45

Barkmeier DT, Senador D, Leclercq K, Pai D, Hua J, Boutros NN, Kaminski RM, Loeb JA (2012) Electrical, Molecular and Behavioral Effects of Interictal Spiking in the Rat. Neurobiol Dis 47(1):92-101

Barttfeld P, Amoruso L, Ais J, Cukier S, Bavassi L, Tomio A, Manes F, Ibanez A, Sigman M (2013) Organization of brain networks governed by long-range connections index autistic traits in the general population. J Neurodev Disord 5 (1):16, doi: 10.1186/1866-1955-5-16

Belmonte MK, Allen G, Beckel-Mitchener A, Boulanger LM, Carper RA, Webb SJ (2004) Autism and abnormal development of brain connectivity. J Neurosci 24(42):9228-9231

Billeci L, Sicca F, Maharatna K (2013) On the application of quantitative EEG for characterizing autistic brain: a systematic review. Front Hum Neurosci 7:442, doi: 10.3389/fnhum.2013.00442

Bjørnæs H, Bakke KA, Larsson PG (2013) Subclinical epileptiform activity in children with electrical status epilepticus during sleep: effects on cognition and behavior before and after treatment with levetiracetam. Epilepsy Behav 27 (1):40-48

Boersma M, Kemner C, de Reus MA (2013) Disrupted functional brain networks in autistic toddlers. Brain Connect 3 (1):41-9, doi: 10.1089/brain.2012.0127

Bosl W, Tierney A, Tager-Flusberg H, Nelson C (2011) EEG complexity as a biomarker for autism spectrum disorder risk. BMC Med 9:18, doi: 10.1186/1741-7015-9-18

Boutros NN (2009) Inter-ictal spikes in psychiatric patients: a controversy in need for resurrection. Clin EEG Neurosci 40 (4):239-244

Boutros NN, Galloway MP, Ghosh S, Gjini K, Bowyer SM (2013) Abnormal Coherence Imaging in Panic Disorder: an MEG Investigation. NeuroReport 24(9):487-49

Boutros NN, Kirollos S, Pogarell O, Gallinat J (2014) Predictive Value of Isolated Epileptiform Discharges for a Favorable Therapeutic Response to Anti-epileptic Drugs in Non-epileptic Psychiatric Patients. J Clin Neurophysiol 31(1):21-30

Burnette CP, Henderson HA, Inge AP, Zahka NE, Schwartz CB, Mundy PC (2011) Anterior EEG asymmetry and the Modifier Model of Autism. J Autism Dev Disord 41(8):1113-1124, doi: 10.1007/s10803-010-1138-0

Canitano R, Zappella M (2006) Autistic epileptiform regression. Funct Neurol 21(2):97-101

Canitano R, Luchetti A, Zappella M (2005) Epilepsy, electroencephalographic abnormalities, and regression in children with autism. J Child Neurol 20(1):27-31

Cantor DS, Thatcher RW, Hrybyk M, Kaye H (1986) Computerized EEG analyses of autistic children. J Autism Dev Disord 16(2):169-187

Catarino A, Andrade A, Churches O, Wagner AP, Baron-Cohen S, Ring H (2013) Task-related functional connectivity in autism spectrum conditions: an EEG study using wavelet transform coherence. Mol Autism 4(1):1, doi: 10.1186/ 2040-2392-4-1 
Chan AS, Sze SL, Cheung MC (2007) Quantitative electroencephalographic profiles for children with autistic spectrum disorder. Neuropsychology 21(1):74-81

Chez MG, Buchanan T, Aimonovitch M (2004) Frequency of EEG abnormalities in age matched siblings of autistic children with abnormal sleep EEG patterns. Epilepsy Behav 5(2):159-162

Chez MG, Chang M, Krasne V, Coughlan C, Kominsky M, Schwartz A (2006) Frequency of epileptiform EEG abnormalities in a sequential screening of autistic patients with no known clinical epilepsy from 1996 to 2005. Epilepsy Behav 8 (1):267-271

Coben R, Clarke AR, Hudspeth W, Barry RJ (2008) EEG power and coherence in autistic spectrum disorders. Clin Neurophysiol 119:1002-1009

Constantino JN (2002) The Social Responsiveness Scale Los Angeles. Western Psychological Services, California

Daoust AM, Limoges E, Bolduc C, Mottron L, Godbout R (2004) EEG spectral analysis of wakefulness and REM sleep in high functioning autistic spectrum disorders. Clin Neurophysiol 115:1368-1373

DeLong R, Nohria C (1994) Psychiatric family history and neurological disease in autistic spectrum disorders. Dev Med Child Neurol 36(5):441-448

Duffy FH, Als H (2012) A stable pattern of EEG spectral coherence distinguishes children with autism from neuro-typical controls - a large case control study. BMC Med 10:64, doi: 10.1186/1741-7015-10-64

Duffy FH, Shankardass A, McAnulty GB, Als H (2013) The relationship of Asperger's syndrome to autism: a preliminary EEG coherence study. BMC Med 11:175, doi: 10.1186/1741-7015-11-175

Ekinci O, Arman AR, Işik U, Bez Y, Berkem M (2010) EEG abnormalities and epilepsy in autistic spectrum disorders: clinical and familial correlates. Epilepsy Behav 17(2):178-182

Elisevich K, Shukla N, Moran J, Smith B, Schultz L, Mason K, Bowyer S (2011) An assessment of MEG coherence imaging in the study of temporal lobe epilepsy. Epilepsia 52:1110-1114

Falter CM, Braeutigam S, Nathan R, Carrington S, Bailey AJ (2013) Enhanced access to early visual processing of perceptual simultaneity in autism spectrum disorders. J Autism Dev Disord 43(8):1857-1866

Findji F, Harrison-Covello A, Lairy GC (1979) Long duration EEG studies in the case of a psychotic child. Electroencephalogr Clin Neurophysiol 46(5):592-600

Frye RE, Butler I, Strickland D, Castillo E, Papanicolaou A (2010) Electroencephalogram discharges in atypical cognitive development. J Child Neurol 25(5):556-566

Gabard-Durnam L, Tierney AL, Vogel-Farley V, Tager-Flusberg H, Nelson CA (2013) Alpha Asymmetry in Infants at Risk for Autism Spectrum Disorders. J Autism Dev Disord. [Epub ahead of print]. PMID:23989937.

Gabis L, Poeroy J, Andriola MR (2005) Autism and epilepsy: cause, consequence, comorbidity, or coincidence? Epilepsy Behav 7:652-656

Gilbert DL (2006) Interobserver reliability of visual interpretation of electroencephalograms in children with newly diagnosed seizures. Dev Med Child Neurol 48(12):1009-10, author reply 1010-1

Gilby KL, O'Brien TJ (2013) Epilepsy, autism, and neurodevelopment: kindling a shared vulnerability? Epilepsy Behav 26 (3):370-374

Gillberg C (1991) The treatment of epilepsy in autism. J Autism Dev Disord 21(1):61-77

Gillberg C, Steffenburg S, Jacobsson G (1987) Neurobiological findings in 20 relatively gifted children with Kanner-Type autism or Asperger Syndrome. Dev Med Child Neurol 29(5):641-649

Gubbay SS, Lobascher M, Kingerlee P (1970) A neurologic appraisal of autistic children: results of a western Australian survey. Dev Med Child Neurol 12:422-429

Hara H (2007) Autism and epilepsy: a retrospective follow-up study. Brain Dev 29(8):486-490

Hartley-McAndrew M, Weinstock A (2010) Autism Spectrum Disorder: Corrleation between aberrant behaviors, EEG abnormalities and seizures. Neurol Int 2(e10):42-47

Hashimoto T, Sasaki M, Sugai K, Hanaoka S, Fukumizu M, Kato T (2001) Paroxysmal discharges on EEG in young autistic patients are frequent in frontal regions. J Med Invest 48(3-4):175-180

Hrdlicka M, Komarek V, Propper L, Kulisek R, Zumrova A, Faladova L, Havlovicova M, Sedlacek Z, Blatny M, Urbane T (2004) Not EEG abnormalities but epilepsy is associated with autistic regression and mental functioning in childhood autism. Eur Child Adolesc Psychiatry 13(4):209-213

Hughes JR, Melyn M (2005) EEG and seizures in autistic children and adolescents: further findings with therapeutic implications. Clinical EEG Neurosci 36(1):15-20

Kagan-Kushnir T, Roberts SW, Snead OC 3rd (2005) Screening electroencephalograms in autism spectrum disorders: evidence-based guideline. J Child Neurology 20(3):197-206

Kanemura H, Sano F, Tando T, Sugita K, Aihara M (2013) Can EEG characteristics predict development of epilepsy in autistic children? Eur J Paediatr Neurol 17(3):232-237

Kanner L (1943) Autistic disturbances of affective contact. Nervous Child 10:217-250

Kawasaki Y, Yokota K, Shinomiya M, Shimizu Y, Niwa S (1997) Electroencephalographic paroxysmal activityies in the frontal area emerged in middle childhood and during adolescence in a follow-up study of autism. J Autism Develop Disord 27(5):605-620

Kayaalp L, Dervent A, Satik S, Uluduz D, Kayaalp IV, Demirbilek V, Ghaziuddin M (2007) EEG abnormalities in West syndrome: correlation with the emergence of autistic features. Brain Dev 29(6):336-345

Lajiness-O'Neill R, Bowyer SM, Moran J, Zillgitt A, Richard AE, Boutros NN (2014) Neurophysiological Findings from Magnetoencephalography in Autism Spectrum Disorder: A Comprehensive Review. Future Neurol 9(3):355-384

Larsson PG, Bakke KA, Bjørnæs H, Heminghyt E, Rytter E, Brager-Larsen L, Eriksson AS (2012) The effect of levetiracetam on focal nocturnal epileptiform activity during sleep-a placebo-controlled double-blind cross-over study. Epilepsy Behav 24(1):44-48

Lewine JD, Andrews R, Chez M, Patil AA, Devinsky O, Smith M, Kanner A, Davis JT, Funke M, Jones G, Chong B, Provencal S, Weisend M, Lee RR, Orrison WW Jr (1999) Magnetoencephalographic patterns of epileptiform activity in children with regressive autism spectrum disorders. Pediatrics 104(3):405-418

Lo-Castro A, Curatolo P (2013) Epilepsy associated with autism and attention deficit hyperactivity disorder: Is there a genetic link? Brain Dev May 29. pii: S0387-7604(13)00162-9. doi: 10.1016/j.braindev.2013.04.013. 
Machado C., Estévez M., Leisman G (2013) QEEG Spectral and Coherence Assessment of Autistic Children in Three Different Experimental Conditions. J Autism Dev Disord. [Epub ahead of print]. PMID:24048514.

Mathewson KJ, Jetha MK, Drmic IE, Bryson SE, Goldberg JO, Schmidt LA (2012) Regional EEG alpha power, coherence, and behavioral symptomatology in autism spectrum disorder. Clin Neurophysiol 123(9):1798-1809, doi: 10.1016/j. clinph.2012.02.061

Maxwell CR, Villalobos ME, Schultz RT, Herpertz-Dahlmann B, Konrad K, Kohls G (2013) Atypical Laterality of Resting Gamma Oscillations in Autism Spectrum Disorders. J Autism Dev Disord. [Epub ahead of print]. PMID: 23624928

Moran JE (2008) MEG Tools available at www.megimaging.com. MEG signal processing, data visualization, MRI integration, Brain imaging and visualization, Detroit

Moran JE, Drake CL, Tepley N (2004) ICA methods for MEG imaging. Neurol Clin Neurophysiol 72:1-6

Moran JE, Bowyer S, Tepley N (2005) Multi-Resolution FOCUSS: A source imaging technique applied to MEG data. Brain Topogr 18:1-17

Murias M, Webb SJ, Greenson J, Dawson G (2007) Resting state cortical connectivity reflected in EEG coherence in individuals with autism. Biol Psychiatry 62:270-273

Ošlejšková H, Dusek L, Makovska A, Rector I (2007) Epilepsia. Epileptiform abnormalities, non-right-handedness, hypotonia and severe decreased IQ are associated with language impairment in autism. Epileptic Disord 9(Suppl 1): S9-18

Ošlejšková H, Dusek L, Makovska A, Pejcochova J, Autrata R, Slapak I (2008) Complicated relationship between autism with regression and epilepsy. Neuroendocrinol Lett 29(4):558-570

Parmeggiani A, Barcia G, Posar A (2010) Epilepsy and EEG paroxysmal abnormalities in autism spectrum disorders. Brain Dev 32(9):783-789

Patry G, Lyagoubi S, Tassinari CA (1971) Subclinical "electrical status epilepticus" induced by sleep in children. Arch Neurol (Chicago) 24:242-252

Peters JM, Taquet M, Vega C, Jeste SS, Fernandez IS, Tan J, Nelson CA 3rd, Sahin M, Warfield SK (2013) Brain functional networks in syndromic and non-syndromic autism: a graph theoretical study of EEG connectivity. BMC Med 11:54, doi: 10.1186/1741-7015-11-54

Pop-Jordanova N, Zorec T, Demerdzieva A, Gucev Z (2010) QEEG characteristics and spectrum weighted frequency for children diagnosed as autistic spectrum disorder. Non-linear Biomed Phys 4(4):1-7

Pressler RM, Robinson RO, Wilson GA, Binnie CD (2005) Treatment of interictal epileptiform discharges can improve behavior in children with behavioral problems and epilepsy. J Pediatrics 146:112-117

Rapin I (1995) Acquired aphasia in children. J Child Neurol 10(4):267-270

Reinhold JA, Molloy CA, Manning-Courtney P (2005) Electroencephalogram abnormalities in children with autism spectrum disorders. J Neuroscience Nursing 37(3):136-138

Rossi PG, Parmeggiani A, Bach V, Santucci M, Visconti P (1995) EEG features and epilepsy in patients with autism. Brain and Development 17(3):169-174

Sánchez Fernández I, Loddenkemper T, Peters JM, Kothare SV (2012) Electrical status epilepticus in sleep: clinical presentation and pathophysiology. Pediatr Neurol 47(6):390-410

Sánchez Fernández I, Chapman KE, Peters JM, Harini C, Rotenberg A, Loddenkemper T (2013) Continuous spikes and waves during sleep: electroclinical presentation and suggestions for management. Epilepsy Res Treat 2013:583531, doi: 10.1155/2013/583531. Epub 2013 Aug 6

Sheikhani A, Behnam H, Mohammadi MR, Noroozian M, Mohammadi M (2012) Detection of abnormalities for diagnosing of children with autism disorders using quantitative electropencephalography analysis. J Med Syst 36:957-963

Small JG (1975) EEG and neurophysiological studies of early infantile autism. Biol Psychiatry 10:385-397

So EL (2010) Interictal epileptiform discharges in persons without a history of seizures: What do they mean? J Clin Neurophysiol 27(4):229-234

Stefanatos GA, Kinsbourne M, Wasserstein J (2002) Acquired epileptiform aphasia: a dimensional view of LandauKleffner syndrome and the relation to regressive autistic spectrum disorders. Child Neuropsychology 8(3):195-228

Stroganova TA, Nygen G, Tsetlin MM, Posikera IN, Gillberg C, Elam M, Orekhova EV (2007) Abnormal EEG lateralization in boys with autism. Clin Neurophysiol 118:1842-1854

Sutton SK, Burnette CP, Mundy PC, Meyer J, Vaughan AE, Charak D (2005) Resting cortical brain activity and social behavior in higher functioning children with autism. J Child Psychol Psychiatry 46(2):211-222

Thatcher RW, North DM, Neubrander J, Biver CJ, Cutler S, DeFina P (2009) Autism and EEG phase reset: deficient GABA mediated inhibition in thalamo-cortical circuits. Dev Neuropsychol 34:780-800

Tierney AL, Gabard-Durnam L, Vogel-Farley V, Tager-Flusberg H, Nelson CA (2012) Developmental trajectories of resting EEG power: an endophenotype of autism spectrum disorder. PLoS One 7(6):e39127, doi: 10.1371/journal. pone.0039127

Tuchman RF, Rapin I (1997) Regression in pervasive developmental disorders: seizures and epileptiform electroencephalogram correlates. Pediatrics 99(4):560-566

Unal O, Ozcan O, Oner O, Akcakin M, Aysev A, Deda G (2009) EEG and MRI findings and their relation with intellectual disability in pervasive developmental disorders. World J Pediatr 5(3):196-200

Valvo G, Baldini S, Brachini F, Apicella F, Cosenza A, Ferrari AR, Guerrini R, Muratori F, Romano MF, Santorelli FM, Tancredi R, Sicca F (2013) Somatic overgrowth predisposes to seizures in autism spectrum disorders. PLoS One 8(9): e75015, doi: 10.1371/journal.pone.0075015

Wang J, Barstein J, Ethridge LE, Mosconi MW, Takarae Y, Sweeney JA (2013) Resting state EEG abnormalities in autism spectrum disorders. J Neurodev Disord 5(1):24, doi: 10.1186/1866-1955-5-24

Wass S (2011) Distortions and disconnections: disrupted brain connectivity in autism. Brain Cogn 75:18-28

Webb SJ, Bernier R, Henderson HA (2013) Guidelines and Best Practices for Electrophysiological Data Collection, Analysis and Reporting in Autism. J Autism Dev Disord. [Epub ahead of print] PMID: 23975145 